\title{
The Effect of Conjoint Behavioral Consultation Program Related Teaching on Problem Behavior and Communication/Social Skills with a Blind and Autistic Child
}

\author{
Gül Kahveci ${ }^{1} \&$ Ayşegül Ataman ${ }^{1}$ \\ ${ }^{1}$ Dr. Fazıl Küçük Faculty of Education, European University of Lefke, Lefke, Turkey \\ Correspondence: Gül Kahveci, Dr. Fazıl Küçük Faculty of Education, European University of Lefke, Lefke, \\ Mersin 10, Turkey. E-mail: gulkahveci@yahoo.com
}

Received: September 20, 2017

Accepted: October 31, 2017

Online Published: November 9, 2017

doi:10.5539/jel.v6n4p372

URL: http://doi.org/10.5539/jel.v6n4p372

\begin{abstract}
Individuals with disabilities display problem behaviors frequently. This case study presents an analysis of the extent to which one student's pattern of multiple problem behaviors and the potential efficacy of Conjoint Behavioral Consultation (CBC) as a model for linking families, schools, and special education settings to address educational concerns in order to reduce problem behaviors, increasing communication and social skills for a child with visual impairment and Autism Spectrum Disorder (ASD). The child with, multiple disabilities his parents, school teachers, and consultant were involved in conjoint consultation, a model of cross-system collaboration to address shared concerns for educational needs. In this structured educational model, parent, teacher, and special education teacher (consultant) worked collaboratively in interdisciplinary joint decision making with extensive input regarding child's individuality. The study incorporated a delayed non-concurrent multiple probe design across behaviors using qualitative explanations in mixed design. Outcome measures included parent and school teachers observations of child functioning across home, school and special education settings as a result of consultation-mediated interventions and social validity indices assessing acceptability and consumer satisfaction. Results suggested the impression that $\mathrm{CBC}$ is a socially valid procedure for addressing concerns of child with multiple disabilities across home, school and special education systems. Both parents and school teacher reported the consultation process to be highly acceptable although limitations with the methodology of single subject design. Research is needed to determine the contexts and conditions under which the model is more or less effective using increased number of participants.
\end{abstract}

Keywords: conjoint behavioral consultation, autism spectrum disorder, problem behavior, functional assessment, delayed non-concurrent multiple baseline method

\section{Visual Impairment and Autism Spectrum Disorder}

It is reported that today many children with multiple disabilities are accepted by large masses, regardless of the degree and complexity of their inadequacy, to take advantage of the best possible training interventions (Cook \& Odom, 2013; Foreman, Arthur-Kelly, Bennett, Neilands, \& Colyvas, 2014). In the case of multiple disabilities of blind autistic children the same researchers stated that the aims involved in educational interventions were significantly different from those of typical-progressing children. In this case, it is highly specialized to design and implement practical, reliable and individualized in-class measurements and treatment interventions. It has been stated that family-teacher and consultant can work together to design intervention process by conjoint behavioral consultation when standard treatments are not effective enough for every situation and environment for children with multiple disabilities (Sheridan, 2000). In particular, it has been stated that conducting individualized behavioral consultation studies for children who do not respond to standardized programs or practices is necessary for school success and positive behaviors to be proliferated and to reduce inappropriate behaviors (Sugai et al., 2000). In many cases of multiple disabilities such as being blind and having ASD concurrently, violent behaviors such as anger, damage to oneself and the environment, incompatibility are manifested in high levels (Kamps, Kravits, Rauch, Kamps, \& Chung, 2000; National Autism Center, 2009). There are several reports on behavioral assessment/evaluation and efficacy of treatments that are included in functional behavioral assessments in order to reduce the difficult behavior and increase the appropriate behavior of children with multiple deficiencies in the field (Hanley, Iwata, \& McCord, 2003; Horner, Carr, Strain, Todd, 
\& Reed, 2002; Lane, Kalberg, \& Shepcaro, 2009; Simpson, 2005). It is explained that the functional behavioral assessment helps the researcher and the practicing teachers to contribute to the formation of the intervention process by designing the treatment based on the function of the behavior by determining the causes of the occurrence and persistence of the challenging behavior (O'Neill et al., 1997). Although functional analysis applications are included in various researches, it is not possible to find any research done on children with ASD who is totally blind.

Repetitive behaviors like blindness tics, such as swinging, hitting the head, turning, rubbing the eyes, holding the hands in the shoulder position, and moving the fingers are frequently encountered in the development of children with visual loss (Noshpitz, 1979; Rutter \& Hersov, 1994). In those with partial vision loss, it is also common for people to see their hands before their eyes and look at the light repeatedly. Echolalia like imitations, the shifts of "I" and "you" pronouns, mutism, delay in independent movements especially in independent motor development, less interest seeking, irrelevant perception of the environment and frequent self-directed behaviors are quite similar to the autistic disorder (Hoevenaars-van den Boom, Antonissen, Knoors, \& Vervloed, 2009). Although the deviation in the development of the blind child is similar to autism, both disorders have separate diagnostic criteria (Rogers, 1998).

Behaviors such as physical anger, harmful self-injury, pica, repetitive behaviors, and anger attacks were the most prevalent determinants of inappropriate behaviors in children with ASD (Horner, Diemer, \& Brazeau, 1992; Reichle, 1990). In particular, anger outbreaks can often occur when a child is treated as a habitual behavior with ASD and such outbreaks of anger appear to cry, shout, break objects, show violence to oneself or the opposite individual (Bolick, 2004). It emphasizes that anger bursts may be related to anxiety, and routines, rules, and limited areas of interest can in fact be seen as a mechanism of coping with anxiety. When these coping mechanisms are stopped, emotional outbursts can emerge as children face various difficulties in controlling their emotions (Myles, 2005).

It is important to assess the potential communication functions used to overcome these challenging behaviors and to receive support from the parents during the design of appropriate treatment procedures (Carr \& Durand, 1985; Durand \& Crinnmins, 1988; Horner \& Day, 1991). Family education is to ensure that it exists within the developmental treatment plan for the child and that it acquires the basic behavioral rules and equipment to implement various teaching strategies (O'Dell, 1985). Teaching strategies in skills acquisition and continuity in criterion based instruction depends on whether pre-determined criteria are met for each skill. It can be said that the parents reached a level of proficiency when they showed $90 \%$ success after two successive applications (Shepard, 1984). This instructional process is maintained by leaving the speed of mastery of the families at their own learning speeds.

\section{CBC Processes}

"Conjoint Behavioral Consultation" can provide a solution-oriented focus in which educators and parents are linked in a collaborative problem-solving process to address the academic, social or behavioral needs of a student are determined together, and the intervention plan is created with a mutual shared responsibility. It is possible to consider $\mathrm{CBC}$ as a flexible and up-to-date educational practice that is used in the transition from the traditional assessment system to the ecological and problem-solving process (Dennis, 2004; Kratochwill \& Stoiber, 2000; Wagner, 2000).

Sheridan and other scholars have pointed out that Conjoint Behavioral Consultation (CBC) has provided a great support for correcting challenging behaviors by implementing comprehensive treatment processes (Gutkin \& Curtis, 1999; Sheridan, Welch, \& Orme, 1996; Bramlett \& Murphy, 1998; Larney, 2003; Sheridan \& Gutkin, 2000; Wagner, 2000). The approach is based on the assumption that behavioral adjustment and academic performance of the student will be positively affected when the home and school systems are in coordination with each other. According to Chen and Downing, the complex situation associated with teaching can require teamwork in more than one area of specialization, since children with visual impairment and additional disabilities (multiple disabilities) can learn differently from their peers (2006). CBC procedural steps include (a) conjoint problem identification, (b) conjoint problem analysis, (c) treatment, and (d) conjoint treatment measures (Sheridan, Dee, Morgan, McCormick, \& Walker, 1996).

The CBC procedures contain both social and academic work and this model can be extended by focusing on the interacting systems in a child's life (home and school). For example; While Colton and Sheridan (1998) addressed compliance with guidelines and anger behaviors, Galloway and Sheridan (1994) included academic behaviors such as completion of math-related work papers and correctness of procedures. There are also research 
on how the $\mathrm{CBC}$ process helps consultees, such as teachers and parents, to overcome student-related problems (Sheridan et al., 2004).

The principles that the consultant establishes with the child in the $\mathrm{CBC}$ stages are to be taken into consideration by Sheridan (Sheridan, Clarke, \& Burt, 2008). There are some communication features that must be considered during the direct implementation of the $\mathrm{CBC}$ processes. For this reason, the consultant's approach to the child needs to be regulated during the $\mathrm{CBC}$ process. Analysis of the interaction is included in the arrangement of the consultant's approach to the child. Analysis of interaction; the analysis of interaction was planned to be carried out through eight behavioral categories including initiatives, confirmations, answers, turn taking, attention, regulation of intensity, affective involvement, and acting independently (Janssen, Riksen-Walraven, \& van Dijk, 2006). The determination of the problem situation in the CBC steps and the inappropriate behaviors of the student can be grouped together under one name which can be called "non-compliance" behaviors (Chandler \& Dahlquist, 2002; Yücesoy \& Erbaş, 2002).

\section{Methodology}

Case Study; a case study example is presented here to demonstrate how first researcher as a consultant can apply $\mathrm{CBC}$ and partner with parents and educators to address the academic and behavioral needs of children with multiple disabilities in a real world context then changing non-compliance behaviors into compliance behaviors. A mixed method has been identified for more realistic use of $\mathrm{CBC}$ intervention in school/home life and in addition to a single-subject design (Part A) a qualitative approach has been preferred (Part B).

The purpose of this research is to demonstrate the effect of $\mathrm{CBC}$ intervention on both reducing the problem behaviors of a blind child with ASD and increasing communication/social skills, and academic skills. Dependent variables of research are; percentage of compliance behaviors upon a) requesting to squeeze of orange juice, b) requesting to play musical instruments, and c) get involved in a conversation by using "because" statements. The independent variable of the research is the $\mathrm{CBC}$ (Part A).

By focusing on a single student, many of the problems behaviors, in a school and home system that impact educational practice, can be systematically studied with the help of multiple baseline designs. Concurrent and non-concurrent multiple baseline designs are similar in that experimental control is based on evaluating behavior across different baselines like students, behaviors, or settings. However, in a non-concurrent multiple baseline design data are not collected simultaneously, and in this research consultant specifically prefer delayed non-concurrent multiple baseline designs across behaviors model in order to show the relation between dependent and independent variables because of the real world context. In the real context situations problem behaviors may appear in any moment during the school year so that no one can guess what kind of problems and when those problems may appear. During the semester parents and educators made their conclusions and priorities about the problem behaviors so that $\mathrm{CBC}$ can be used for delivering interventions with diverse problems. Rest of the problem behaviors handled in part B.

The following behaviors in part $\mathrm{B}$ that appeared at different times in the research process and identified as problem behaviors were dealt with by $\mathrm{CBC}$ intervention and appeared to be qualitatively handled in the research are; non-compliance behavior upon requesting to perform toilet skills independently at school and at home, refuse to sleep in his bed, burping inappropriately after meal, penis touching in the class and not responding to academic questions.

Because internal validity and social acceptance procedures have great importance for proving quality of study researchers include related data. Multidimensional internal validity studies have large implications because it is not possible for the investigator to use the experimental design without predefined internal validity studies to establish the functional relationship between the independent variable and the dependent variable (Dave \& Schneider, 1998). Dane and Schneider set out potential dimensions when evaluating internal validity. These dimensions of consultation processes are; (a) adherence, (b) exposure, (c) quality of delivery, (d) program differentiation, and (e) participant responsiveness.

In this section, the design of the research, the experiment, the means of collecting the information used, the process of the experiment and the analysis of the data are included.

\subsection{Description of the Design}

The single-subject design called "delayed non-concurrent multiple baseline design" by Watson and Workman has been put to the use of researchers with increased flexibility to reduce the length of start-up data or to add new behaviors, situations or subjects (1981). Researchers like Harvey, May and Kennedy (2004) have included "non-concurrent multiple baseline designs" to their work. The design includes a group A-B design, where the 
variable amount of time is spent on the condition. The start-up data in the first stage has no connection with the data in the other stages. A first step in this design is the identification of what constitutes each tier (i.e., baseline-to-intervention) of the analysis.

During baseline, repeated measures of the dependent variables occur to establish data trends prior to intervention procedures. Following the baseline period, an intervention procedure is introduced on one tier. Repeated observations continue just like in baseline to measure what changes, if any, occur in the levels of the dependent variables. If systematic changes in the dependent variables are seen each time that the intervention procedure is introduced to a specific tier, but not otherwise, then a functional relation between independent and dependent variables has been established.

\subsection{Participant}

A 13-year-old male blind student with ASD continued to attend the special multi-disability class in the school for visually impaired students attend, called Mitat Enç Primary School in the 2008-2009 academic year were selected as the participant of this research. A special education teacher and two trainee teachers who work in Mithat Enç Primary School are giving lectures to the participant. The mother of the child is a Turkish teacher, and his father is a physics teacher. Participant student can tend to answer the questions asked by one word sentence. He can sing his favorite songs partially, can rhythm in limited forms, and participate in the lesson in a very limited manner.

Detailed information about the subject was collected by using the Ecological Assessment Form and Communication Skills Information Collection Form prior to the intervention. These data are presented in the 2nd meeting of 2/11/2010 and the 3rd meeting of 3/11/2010 respectively. The score from the Child Behavior Control Chart is 25. Consequences are: "Do not take lessons, be suspicious, threaten people, physically attack people, often scream, often feel sick, feel like they expel other people, destroy/damage personal belongings of family or other children, he cannot be good with other children, his mood or emotions change suddenly, he speaks poorly if speaks, he experiences anger explosions, he needs attention at a high level, his studies at school are very weak, he does not conform to school rules, cannot sit in place, comes against the rules at home, is stubborn, behaves impulsively, often discusses."

\subsection{Settings}

Intervention practices were carried out in Mitat Enç Primary School, a private clinic for children with special needs and subject's home environment. Mitat Enç Primary School; subject's class is on the third floor of the school. The class is opposite the stairs and there is another class on the left. The classroom is of an average size of 10 square meters with high ceilings and has 3 double-decker rows, 3 book shelves, a teacher's desk and a trash bin.

Clinic; treatment were applied in the clinic environment consist of kitchen, individual and group rooms. The kitchen consists of 15 square meters of two tables, 6 chairs, a refrigerator, a trash can, a potato-onion basket, a wall clock and a kitchen counter with an average of 4 meters in length. It is high enough for the subject student to be able to work comfortably on it. The subject student can easily reach the faucet and the sink located in the counter.

\subsection{Data Collection Tools for the Subject}

1) Ecological Evaluation Form: The form was developed by the researcher using the sources (Ford, 1989; Witt, Elliot, Daly, Gresham, \& Kramer, 1997).

It is planned that the form will be used for collecting the first preliminary information about the student from family and classroom teachers in different sub-ecosystems such as home, school and community. The form was used to identify areas of interest for the student, areas where the student was strong, and data about the subject's greatest needs were collected.

\section{2) Child Behavior Control Chart}

It is planned that the form will be used as the first preliminary information about the severity and diversity of inappropriate behaviors of the subject (Quay \& Perterson, 1996; Kaner \& Çiçekçi, 2000).

\section{3) Communication Skills Information Collection Form}

The purpose of the form is to determine the performance of communication skills; its functional use, recipient, expressive language and social interaction. There are 19 questions in the section "Functional Use of Communication", 19 in the "Receptive Language" section, 11 in the "Expressive Language" section and 11 in the 
"Social Interaction" section. Developed specifically for children with ASD by the researcher using the sources (Silver, 2005; Witt, Elliot, Daly, Gresham, \& Kramer, 1997).

\section{4) Functional Analysis Forms}

For forms of Functional Evaluation of Behavior, Erbaş, Kırcaali İftar and Tekin-İftar's "Functional Evaluation" book (2011) were used. Later forms were given focus group work with three volunteer families who have children with ASD and the final form was prepared accordingly. Behavioral explanations for ease of use of forms have been expressed visually to be easily perceivable and fillable.

The forms of the groups such as control, demand, interest and reinforcement have been added in order to retest the hypothesis and to perform functional analysis. The implementation of the analysis forms was carried out using Ford's work (Ford, 1989). The related subtitles are;

4a) Functional Analysis Form, Definition of Problem and Determination of Priorities.

4b) Functional Analysis, The history and quality of life of the student.

4c) Functional Analysis-Event Record, Functional Analysis-ABC Form, Functional Analysis-“compliance behavior upon request" observation. It has been inspired by four standard parts of the Form Iwata (Iwata, Roscoe, Zarcone, and Richman, 2002). These are; 1) Control 2) Concrete reinforcement 3) Demand 4) Interest / attention. The developed form contains data collection areas that specify the number of repetitions, marker behaviors, which of the four cases it represents, the number of repetitions that need to be repeated until reaching a fixed level, and so on. "E" (yes) means that the marker behaviors occur, and " $\mathrm{H}$ " (no) marker behaviors do not occur. The form was created by using fixed time interval. The observation period is 5 minutes and each interval is stated to be half a minute. The form can be observed as a whole on the form, as well as the information on which form of the behavior occurred in the minute. At the bottom of the form there are possible problem behaviors and explanations of these behaviors.

4d) Functional Analysis-Hypothesis Development. There is a definite decision about the hypothesis of the formal hypothesis.

4e) Functional Analysis-Systematic Treatment Plan. The form is to create a systematic intervention based on the objective hypothesis.

4f) Functional Analysis - Group Meeting / Agenda. The objective of the form is to obtain data that includes the implementation and results of the decisions taken at the previous meeting, the new agenda items, the decisions taken, the sharing of responsibilities, and the timing of the next meeting as consultant interview form.

4g) Functional Analysis - Evaluation of the Plan. It is the evaluation of the intervention plan applied after the application of planned instruction. Whether positive changes observed in the form, whether the developed plan is followed, whether the hypothesis is still correct, the expression of the teaching strategy, which has been passed or completely abandoned, has taken place.

5) Constant timedelay procedure material-causal relationship study. The purpose of the form is to determine the performance of the student for verbally expressing the causal relationship. This test was developed by the researcher.

When the form questions were developed, 100 causal relation relations were written and 10 causal relations were determined with unselected assignment method. Beside the measure there is the answer that the student can give. This form of response has been formulated to be error-free so as to cause the student to get + and pass on to the next question.

The use of the form is as follows; the questions on the form were read by students in turn. When the fixed waiting time teaching process is applied and the correct answers are given in 10 questions in succession, the student has met the criterion and the teaching process is terminated. If the student does not respond to the question, is silent, or gives the wrong answer, it is marked on the chart and all the steps starts from the beginning.

6) Example of a Science Informative Text with Comprehension Questions. The purpose of the text is to present a science topic to subject and prove to the special education teacher that subject can learn if we use high quality instructions.

7) Criteria-dependent measure tool associated with the topic of our bones. It contains 10 questions and their answers. The science topic is related to bones in our body, names and functions. In the development of the form, the criterion-dependent measure tool was prepared using the song related to bones. The text, song and the 
criterion-dependent measure tool was developed by the researcher with a criterion of $3 / 4$. The use of the form is as follows; an evaluation was made one day after the 45 minutes (one lesson hour) of the song on Form 6 was shared. The questions on the form were read in order and the correctness of the answers was recorded.

\subsection{Data Collection Tools for the Family and the Teacher}

1) Family/Teacher Evaluation Form (Before/After) - Qualification Before and After Visual Presentations. The purpose of the form is to determine whether the family and teacher need an informative visual presentation, and to repeat the form before and after the presentation to determine whether the visual presentation is useful for the client.

2) Family / Teacher Follow-up Screening Form, Evaluation of the Post-Instruction Counseling Process. The purpose of the form is to determine the quality of teaching process. When the form was developed, 9 questions were utilized. The questions were developed by the researcher.

3) Social Validity Questions-Intervention Effectiveness. The purpose of the form is to determine the client satisfaction associated with the intervention to determine the effectiveness of the intervention. There are 8 questions in the form.

4) Social Validity Questions-Intervention Effectiveness-Volunteer Observers Form. The purpose of the form is to include opinions of external observers in order to avoid bias in their work of social validity.

\subsection{Data Collection Tools Used for Researcher Consultant in Research}

1) Interaction Analysis-Investigator Counselor Self-Monitoring. The formative objective is to determine the effectiveness of the researcher's interaction as a consultant (Nelson, van Dijk, Oster, \& McDonnell, 2009; Janssen, Riksen-Walraven, \& van Dijk, 2003a, 2003b; Janssen, Riksen-Walraven, \& van Dijk, 2004; Janssen, Riksen-Walraven, \& van Dijk, 2006). It consists of eight steps. These steps are; initiation, verification/approval, answers, order taking/turnover, attention, intensity control, emotional participation and independent behavior.

2) Coordination of the Counselor's Approach to Counseling in CBC Process Internal validity Observer Observation Form (Interaction analysis). The objective of the form is to determine whether the interaction the consultant has undertaken to support internal validity has been carried out as planned. During the development of the form, the "Interaction Analysis-Observation of the Researcher's Counselor Self" Record sections were added as $+/$ - for observers using 1-. The steps of the analysis of the interaction have been converted into the observation form by the researcher.

\subsection{A quick Informative Procedure Applied before CBC}

\section{Preparation, Development and Application of Visual Teaching Material Used to Inform Family and Teachers}

The study begins with a semi-structured visual teaching material to inform family and teachers about CBC, ASD and related treatment processes. The aim of this application is to have a common language for collaborative participation in CBC processes. The visual presentation was carried out with the family in the clinic and with the teacher in Mithat Enç primary school. The process was completed at four meetings. The same process was carried out for the family in four meetings and information about the participant and related problem behaviors was obtained by using the data collection tools developed for the participant. Additionally, direct observations were performed in Mithat Enç primary school by the consultant.

\section{Implementation Steps of CBC Processes}

1) Consultation negotiations. $\mathrm{CBC}$ processes started with consultation negotiations. The purpose of the preliminary consultation talks; is to develop cooperation with family and educators. Discussing how the interviews/sessions will take place, summarizing the roles of family and educators, and trying to determine the general problem behaviors, needs and strengths of the child are addressed in this step.

2) Determination of problem behaviors. Includes the process of determining problem behaviors together. In the research, it has been preferred to use various inappropriate behaviors grouped under one name which is called non-compliant behaviors.

3) $\mathrm{CBC}$ problem analysis. Initiation data were collected when determining the target behavior set for the participant or achieving the desired performance level.

4) Functional analysis used in the CBC process. In this study, it was decided to set it to be 5 minutes for direct observation of inappropriate/non-compliant behaviors, and the number of sessions required to determine the function of the inappropriate behavior was maintained for up to 3 consecutive stable trials, the observation 
period corresponding to 15 minutes. After obtaining consistent functional analysis data, the hypothesis is confirmed.

5) Decision that the problem behavior and its function are determined clearly after the functional analysis. Operational $\mathrm{CBC}$ applications in which the positive behavior modification system is included must first be assured of problem behavior.

5a) Problem behaviors and explanations: The cause of problem behavior; It was determined to avoid the request. Non-compliant behaviors/indicator behaviors involved in the research: intense screaming and screaming for 5 seconds and over, hitting, biting, kicking behaviors, physical rejection of 5 seconds or longer, one or more self-harms, destruction of objects: destructive or disturbing behavior includes one or more repetitive physical violence and inappropriate speech.

5b) Behavioral consequences: The effects of the CBC intervention were based on observing the child's performance. Behaviors expected from the child are described as follows: Behavioral consequences are that the child fulfills the directive/request by creating a zero level of non-compliant behaviors/indicator behaviors after the request. Three of these behavioral outcomes have been tried to be expressed by a delayed non-concurrent multiple design graphic.

\section{Part A:}

\section{Target behaviors represented by non-concurrent multiple baseline design research method}

The first target behavior was determined by a joint decision to be appropriate for the cultural structure of the family. On weekend breakfasts, family gather together and social cohesion is provided. The subject who likes to drink orange juice in preparing breakfast was assigned to prepare this drink for the whole family and the first target behavior was determined in the consultation talk made with family.

\section{CBC process to achieve the first behavioral result related to orange pressing behavior when requested}

1) Behavioral result: When consultant asks the participant to perform pressing orange juice skill that contains 10 steps which can be considered as a morning routine in a social activity taking place in the home environment, the child fulfills the request without showing any indicator behaviors/non-compliance.

\section{1) Intervention Decision and Application}

The Rationale of the Intervention Decision: The orange-pressing behaviors skill is not only an opportunity for the development of communication within the family, but it also requires the child to be intervened in relation to tactile system malfunction. Thus, by adjusting the level of the sensory stimulus, feedback can be obtained that produces appropriate behavior (Flanery \& Horner, 1994; Mace, Shapiro, \& Mace, 1998; Tustin, 1995). The tactile approach gives the impression that it resembles similar applications to shaping processes. The behavior closest to the desired behavior in the shaping process is reinforced to support the desired new behavior. The shaping process is utilized in the teaching of a new skill that the child has never done before (Chandler \& Dahluist, 2002, p. 402). At the same time, the shaping process can be used together with stimulus control to provide children with academic and social behavior (Chandler \& Dahluist, 2002, p. 404). The researcher provided information about the skill to the father, presented the orange pressing steps, modeled the processes of the target skill, and undertook the role of the investigating child when presenting the father skill. Then, as a consultant researcher gave feedback to the father at each step, and when the father did two consecutive times and gets $90 \%$ correct level, the teaching process was terminated and data collection was continued. While developing the teaching steps of the skill, a resource kit was used for children affected by visual impairment (Hagood, 1997).

The $\mathrm{CBC}$ intervention was initiated again when the first three baseline data related to the "percentage of behavior compliance" when "orange pressing was requested" was consistent. When the $100 \%$ criterion was met in succession after the intervention, data from the generalization and maintenance phase were collected.

\section{CBC process performed to reach the second behavioral result related to chord/ rhythm holding and percussion instruments when requested}

In interviews with family and educators, it was determined that the subject had a strong sense of singing and rhythm. However, since the subject used percussion instruments improperly in the classroom environment, it was decided that there should be a goal of holding the rhythm, as other near classes get annoyed from the noise. In interviews with family, drumming and percussion instruments and rhythm holding were considered as leisure activities and by this way the participant has the opportunity to increase the quality of life and to have a chance for proper communication. 
1) Behavioral result: When the participant is requested to play a musical instrument (once a week) he increases his participation in the process without indicator behaviors/non-compliance behaviors and at the same time advances his interaction with the educators and the family. The generalization is planned to be in the school and in the house.

\section{2) Intervention Decision and Application}

It was started to intervene after determining that the cause of the inappropriate behavior according to functional analysis was "avoidance". The avoidance functions of behavior change processes were again supported by using the literature.

The information obtained is summarized as follows: Differential reinforcement of incompatible behavior methodology is selected from applied behavior analysis approach, which is reinforcing behavior that is topologically incompatible with the intended behavior. Motivational studies have been included at varying intervals along with reinforcements. Short cues have been used in motivation studies, e.g., "We are very happy when you play saz / bendir / darbuka", "Aunt / mother / sister is very happy."

\section{3) The third problem associated with emergency intervention when requested is the $\mathrm{CBC}$ process to achieve the behavioral outcome}

A repetition of the destructive behavior, which was once exhibited three months ago, has emerged in the classroom, dining hall and at home.

The reason for the creation of an intervention plan is that the participant starts to exhibit destructive behaviors such as screaming, biting, kicking, slapping, "saying that the aliens are coming". For this reason, it has been determined that participant needs to develop his communication behaviors.

According to the functional analysis of the behavior, avoidance from aliens is related to teaching "because" where cause-effect relations have been tried to be provided. "Because" is a concept as well as a feature of being a conjunction (Chandler \& Dahluist, 2002, p. 405). According to the same authors, it is not possible to teach some concepts by describing them; like the concept of color red. In this case, teaching is carried out by giving many examples (Chandler \& Dahluist, 2002, p. 406). So that, it is planned to use the "cause" conclusions with "because" to explain that there is no aliens and accordingly it is not possible to harm people.

The necessity of additional teaching was born short after the fact that the subject did not know the concept of "because". For this reason, participant were asked to answer 10 "why" questions. After having 3 consecutive 100\% correct answers the generalization phase has been carried out. In the generalization phase, "The aliens cannot hurt us because..." question was asked. After getting the answer "The aliens cannot hurt us because there are no aliens." as a reply, the generalization phase was terminated.

\section{Part B:}

In the classroom environment, the child positively overcame the unwanted situation which was expressed as a problem behavior according to the teacher by performing the toilet skill independently. Trainee teachers in the class who did not sympathize with the participant's "burp" behavior changed positively by teaching participant to say "Don't burp because girls don't like it". Likewise, subject's penis touching behavior changed positively by teaching subject to say "Don't touch penis because girls don't like it". The trainee teachers, who hesitated from the behaviors of participant such as slapping, kicking and yelling at the beginning of the practice, shared their sympathy with the researcher after the CBC program related teaching.

\section{Interobserver and Procedural Reliability}

In multidimensional internal validity study, (a) adherence (b) exposure, (c) the nature of the intervention presentation, (d) differentiation of the intervention program, and (e) participant feedback dimensions. In this study, interobserver reliability was calculated by selecting from eight different treatment and initiation levels. Attempts have been made to determine inappropriate and appropriate behaviors on demand. The external validity in the study has been tried to be revealed by the maintenance data. Social validity studies have been performed by the family, classroom teacher and three independent volunteers. 


\section{Findings and Discussion}

\section{Part A:}

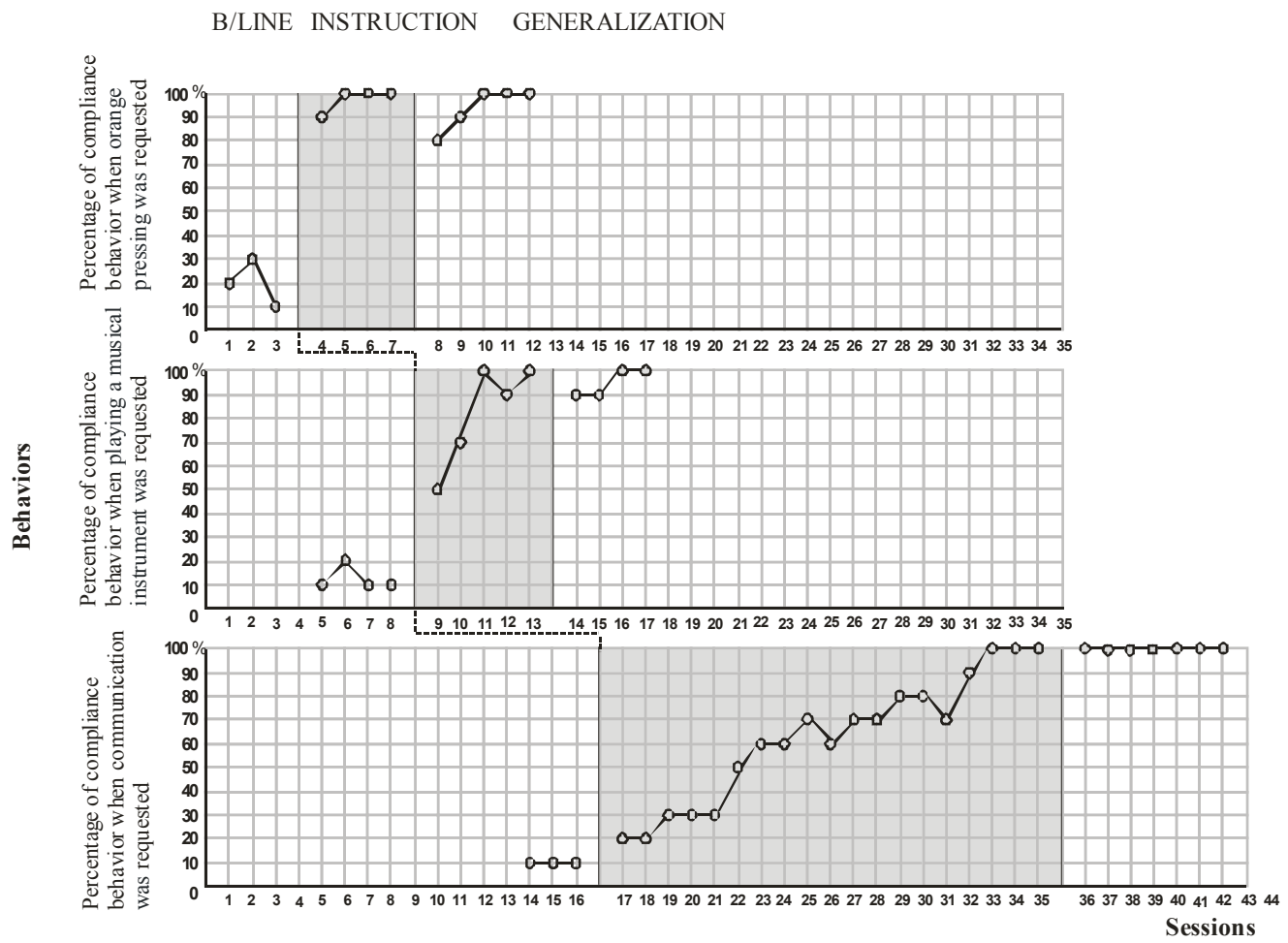

Figure 1. Delayed non-concurrent multiple baseline design across behaviors graphic

The findings of the $\mathrm{CBC}$ processes have been found a decrease in problem behaviors which functions for escape and increase in communication behaviors. At the end of the intervention, not only in the home environment where anger attacks did diminish, but morning breakfasts became a chance for appropriate communication processes.

\section{Part B:}

In the classroom environment, the child positively overcame the unwanted situation which was expressed as a problem behavior by the teacher by performing the toilet skill independently. Trainee teachers in the class who did not sympathize participant's "burp" behavior changed positively by teaching participant to say "Don't burp because girls don't like it”. Likewise, participant's penis touching behavior changed positively by teaching participant to say "Don't touch penis because girls don't like it". The trainee teachers, who hesitated from the behaviors of participant such as slapping, kicking and yelling at the beginning of the practice, shared their sympathy with the researcher after the CBC program related teaching.

The multidimensional internal validity study, social validity studies performed by the family, classroom teacher and three independent volunteers resulted positively with high levels.

\section{Conclusions}

It is possible to say that these behavior changes at the home and in classroom environment affects the interaction of the subject with his environment positively. The disappearance of anger explosions and positive changes in the communication, suggests that the CBC practices in this study have resulted positively in subject's ecological system. Moreover, the positive behavioral changes achieved in the CBC practices remain consistent over time. Family and classroom teachers also shared positive views on consultation process (acceptability) and outcomes (effectiveness). CBC has been expressed by family and teachers as being consistently acceptable and effective in reducing subject's inappropriate behavior and developing communication skills. Following this positive approach, family and teachers expressed their willingness to reuse the CBC practices, and the process considered to be applicable to other families and teachers as their recommendation. 
Although there are difficulties in the generalization of single subject designs, the collected data show significant results for educational applications. Consistent with similar research, the result is supported by the fact that the child benefits from home school co-operation and the family participation in the training process (Shapiro, Miller, Sawka, Gardill and Handler, 1999; Christenson and Sheridan 2001; Wilkinson, 2003; Wilkinson, 2006). In $\mathrm{CBC}$ practice, the social validity of the participant families was determined to be high (Carr, Levin et al., 1999) because the decrease in problem behaviors and the increase in compliance-related behaviors were frequent. The literature on the field is in accordance with the results of this study. It can be beneficial to compare well-controlled treatment programs with each other for future studies. Meta-analyzes studies also provide valuable information about the effectiveness of ASD treatments.

\section{References}

Bolick, T. (2004). Asperger Syndrome and Young Children: Building Skills for the Real World. Gloucester, MA: Fair Winds Press.

Bramlett, R. K., \& Murphy, J. J. (1998). School psychology perspectives on consultation: Key contributions to the field. Journal of Educational and Psychological Consultation, 9, 29-55. https://doi.org/10.1207/s1532768xjepc0901_2

Carr, E. G., \& Durand, V. M. (1985). Reducing behavior problems through functional communication training. Journal of Applied Behavior Analysis, 18, 111-126. https://doi.org/10.1901/jaba.1985.18-111

Carr, E. G., Levin, L., McConnachie, G., Carlson, J. I., Kemp, D. C., Smith, C. E., \& Magito McLaughlin, D. (1999). Comprehensive multisituational intervention for problem behavior in the community: Long-term maintenance and social validation. Journal of Positive Behavior Interventions, 1, 5-25. https://doi.org/10.1177/109830079900100103

Chandler, L. K., \& Dahlquist, C. M. (2002). Functional Assessment: Strategies to Prevent and Remediate Challenging Behavior in School Settings (3rd ed.). Merill Prentice Hall.

Chen, D., \& Downing, J. E. (2006). Tactile Strategies for Children. New York: AFB Press.

Christenson, S. L., \& Sheridan, S. M. (2001). Schools and families: Creating essential connections for learning. New York: Guilford Press.

Colton, D. L., \& Sheridan, S. M. (1998). Conjoint behavioral consultation and social skills training: Enhancing the play behaviors of boys with attention deficit hyperactivity disorder. Journal of Educational and Psychological Consultation, 9(1), 3-28. https://doi.org/10.1207/s1532768xjepc0901_1

Cook, B. G., \& Odom, S. L. (2013). Evidence-based practices and implementation science in special education. Exceptional Children, 79, 135-144. https://doi.org/10.1177/001440291307900201

Dave, A. V., \& Schneider, B. H. (1998). Program integrity in primary and early secondary prevention: Are implementation effects out of control? Clinical Psychology Review, 18(1), 23-45.

Dennis, R. (2004). So far so good? A qualitative case study exploring the implementation of consultation in schools. Educational Psychology in Practice, 20, 17-29. https://doi.org/10.1080/0266736042000180384

Durand, V. M., \& Crimmins, D. B. (1988). Identifying the variables maintaining self injurious behavior. Journal of Autism and Developmental Disorders, 18, 99-117. https://doi.org/10.1007/BF02211821

Erbaş, D., İftar, E. T., \& İftar G. K. (2011). İşlevsel Değerlendirme (Davranış Sorunlarıyla Başa Çıkma ve Uygun Davranışlar Kazandırma Süreci, 5, Baskı, Kök Yayınevi).

Flannery, K. B., \& Horner, R. H. (1994). The relationship between predictability and problem behavior for students with severe disabilities. Journal of Behavioral Education, 4(2), 157-176. https://doi.org/10.1007/BF01544110

Ford, A. (1989). The Syracuse Community Referenced Curriculum Guide for Students with Moderate and Severe Disabilities. Paul Brookes.

Foreman, P., Arthur-Kelly, M., Bennett, D., Neilands, J., \& ve Colyvas, K. (2014). Observed changes in the alertness and communicative involvement of students with multiple and severe disability following in-class mentor modelling for staff in segregated and general education classrooms. J Intellect Disabil Res., 58(8), 704-720. https://doi.org/10.1111/jir.12066 
Galloway, J., \& Sheridan, S. M. (1994). Implementing scientific practices through case studies: Examples using home-school interventions and consultation. Journal of School Psychology, 32, 385-413. https://doi.org/10.1016/0022-4405(94)90035-3

Gutkin, T. B., \& Curtis, M. (1999). School based consultation theory and practice: The art and science of indirect service delivery. In C. R. Reynolds, \& T. B. Gutkin (Eds.), Handbook of school psychology (3rd ed.). New York: Wiley.

Hagood, L. (1997). Communication: A Guide for Teaching Students with Visual and Multiple Impairments. Austin, TX: Texas School for the Blind and Visually Impaired Print.

Hanley, G. P., Iwata, B. A., \& McCord, B. E. (2003). Functional analysis of problem behavior: A review. J Appl Behav Anal, 36(2), 147-185. https://doi.org/10.1901/jaba.2003.36-147

Harvey, M. T., May, M. E., \& Kennedy, C. H. (2004). Non-concurrent Multiple Baseline Designs and the Evaluation of Educational Systems. Journal of Behavioral Education, 13(4), 267-276. https://doi.org/10.1023/B:JOBE.0000044735.51022.5d

Hoevenaars-van den Boom, M. A. A., Antonissen, A. C. F. M., Knoors, H., \& Vervloed, M. P. J. (2009). Differentiating characteristics of deafblindness and autism in people with congenital deafblindness and profound intellectual disability. Journal of Intellectual Disability Research, 53(6), 548-558. https://doi.org/10.1111/j.1365-2788.2009.01175.x

Horner, R. H., \& Day, H. M. (1991). The effects of response efficiency on functionally equivalent competing behaviors. Journal of Applied Behavior Analysis, 24(4), 719-732. https://doi.org/10.1901/jaba.1991.24-719

Horner, R. H., Carr, E. G., Strain, P. S., Todd, A. W., \& Reed, H. K. (2002). Problem behavior interventions for young children with autism: A research synthesis. Journal of Autism and Developmental Disorders, 32, 423-446. https://doi.org/10.1023/A:1020593922901

Horner, R. H., Diemer, S. M., \& Brazeau, K. C. (1992). Educational support for students with severe problem behaviors in Oregon: A descriptive analysis from the 1987-1988 school year. The Journal of the Association of Persons with Severe Handicaps, 17(3), 154-169. https://doi.org/10.1177/154079699201700304

Iwata, B. A., Roscoe, E. M., Zarcone, J. R., \& Richman, D. M. (2002). Environmental determinants of self-injurious behavior. ISO 690. https://doi.org/10.1037/10457-005

Janssen, M. J., Riksen-Walraven, J. M. A., \& Van Dijk, J. P. M. (2003a). Contact: Effects of an intervention program to foster harmonious interactions between deafblind children and their educators. Journal of Visual Impairment and Blindness, 97(4), 215-229.

Janssen, M. J., Riksen-Walraven, J. M. A., \& Van Dijk, J. P. M. (2003b). Towards a diagnostic intervention model for fostering harmonious interactions between deafblind children and their educators. Journal of Visual Impairment and Blindness, 97(4), 197-241.

Janssen, M. J., Riksen-Walraven, J. M. A., \& Van Dijk, J. P. M. (2004). Enhancing the interactive competence of deafblind children: Do intervention effects endure? Journal of Developmental and Physical Disabilities, 16(1), 73-95.

Janssen, M. J., Riksen-Walraven, J. M. A., \& van Dijk, J. P. M. (2006). Applying the Diagnostic Intervention Model for fostering harmonious interactions between deafblind children and their educators: A case study. Journal of Visual Impairment and Blindness, 100(2), 91-106.

Kamps, D., Kravits, T., Rauch, J., Kamps, J. L., \& Chung, N. (2000). A prevention program for students with or at risk of ED: Moderating effects of variation in treatment and classroom structure. Journal of Emotional and Behavioral Disorders, 8, 141-154. https://doi.org/10.1177/106342660000800302

Kaner, S., \& Çiçekçi, A. U. (2000). Gözden Geçirilmiş Davranış Problemleri Kontrol Listesi’nin Türkçe’ye Uyarlanması. Özel Eğitim Dergisi, 2(4), 23-34.

Kratochwill, T. R., \& Stoiber, K. C. (2000). Uncovering critical research agendas for school psychology: Conceptual dimensions and future directions. School Psychology Review, 29, 591-603.

Lane, K. L., Kalberg, J. R., \& Shepcaro, J. C. (2009). An examination of quality indicators of function-based interventions for students with emotional or behavioral disorders attending middle and high schools. Exceptional Children, 75, 321-340. https://doi.org/10.1177/001440290907500304 
Larney, R. (2003). School-based consultation in the United Kingdom: Principles, practice and effectiveness. School Psychology International, 24, 5-19. https://doi.org/10.1177/0143034303024001518

Mace, A. B., Shapiro, E. S., \& Mace, F. C. (1998). Effects of warning stimuli for reinforcer withdrawal and task onset on self-injury. Journal of Applied Behavior Analysis, 31(4), 679-682. https://doi.org/10.1901/jaba.1998.31-679

Myles, B. S. (2005). Children and youth with Asperger Syndrome: Strategies for success in inclusive settings. Thousand Oaks, CA: Corwin Press.

National Autism Center. (2009). National standards report. The National Standards Project: Addressing the need for evidence-based practice guidelines for autism spectrum disorders. Randolph, MA: Author.

Nelson, C., van Dijk, J., Oster, T., \& McDonnell, A. P. (2009). Child-guided strategies: The van Dijk approach to assessment for understanding children and youth with sensory impairments and multiple disabilities. Louisville, KY. American Printing House for the Blind. Published.

Noshpitz, J. D. (1979). Basic Handbook of Child Psychiatry: Disturbances in Development. New York: Basic Books Inc.

O'Dell, S. L. (1985). Progress in parent training. Progress in behavior, 10, 57-108. https://doi.org/10.1016/B978-0-12-535619-0.50006-X

O’Neill, R. E., Horner, R. H., Albin, R. W., Sprague, J. R., Storey, K., \& Newton, J. S. (1997). Functional Assessment and Program Development for Problem Behavior (2nd ed.). Pacific Grove, CA: Brooks/Cole Publishing Company.

Quay, H. C., \& Peterson, D. R. (1996). Revised behavior problem checklist (Professional manual). Odesa, PAR, Edition: Professional manual.

Reichle, J. (1990). National Working Conference on Positive Approaches to the Management of Excess Behavior: Final report and recommendations. Minneapolis, MN: Institute on Community Integration, University of Minnesota.

Rogers, S. J. (1998). Empirically supported comprehensive treatments for young children with autism. Journal of Clinical Child Psychology, 27(2), 168-179. https://doi.org/10.1207/s15374424jccp2702_4

Rutter, M., Taylor, E., \& Hersov, L. (Eds). (1994). Child and Adolescent Psychiatry, Modern Approaches. Oxford: Blackwell Scientific.

Shapiro, E. S., Miller, D. N., Sawka, K., Gardill, M. C., \& Handler, M. W. (1999). Facilitating the inclusion ofstudents with EBD into general education classrooms. Journal of Emotional and Behavioral Disorders, 7(2), 83-93. https://doi.org/10.1177/106342669900700203

Shepard, R. N. (1984). Ecological Constraints on Internal Representation: Resonant Kinematics of Perceiving, Imagining, Thinking and Dreaming. Psychological Review, 91, 417-447. https://doi.org/10.1037/0033-295X.91.4.417

Sheridan, C. D. L., \& Sheridan, S. M. (1998). Conjoint behavioral consultation and social skills training: Enhancing the play behaviors of boys with attention deficit hyperactivity disorder. Journal of Educational and Psychological Consultation, 9(1), 3-28. https://doi.org/10.1207/s1532768xjepc0901_1

Sheridan, S. M., \& Gutkin, T. B. (2000). The ecology of school psychology: Examining and changing our paradigm for the 21st Century. School Psychology Review, 29(4), 485-501.

Sheridan, S. M., Clarke, B. L., \& Burt, J. D. (2008). Conjoint Behavioral Consultation: What do we know and what do we need to know? In W. Erchul, \& S. (Eds.), Handbook of research in school consultation: Empirical foundations for the field. New York, NY: Erlbaum Press.

Sheridan, S. M., Dee, C. C., Morgan, J. C., McCormick, M. E., \& Walker, D. (1996). A multimethod intervention for social skills deficits in children with ADHD and their parents. School Psychology Review, 25(1), 57-76.

Sheridan, S. M., Erchul, W. P., Brown, M. S., Dowd, S. E., Warnes, E. D., Marti, D. C., ... Eagle, J. W. (2004). Perceptions of helpfulness in conjoint behavioral consultation: Congruence and agreement between teachers and parents. School Psychology Quarterly, 19(2), 121-140. https://doi.org/10.1521/scpq.19.2.121.33308

Sheridan, S. M., Welch, M., \& Orme, S. F. (1996). Is consultation effective? A Review of Outcome Research. Remedial and Special Education, 17(6), 341-354. https://doi.org/10.1177/074193259601700605 
Silver, K. (2005). Assessing and Developing Communication and Thinking Skills in People with Autism and Communication Difficulties: A Toolkit for Parents and Professionals, Bölüm II. Jessica Kinksley Publishers.

Simpson, R. L. (2005). Evidence-based practices and students with autism spectrum. Focus Autism Other Dev Disabl, 20(3), 140-149. https://doi.org/10.1177/10883576050200030201

SM Sheridan, S. M. (2000). Considerations of multiculturalism and diversity in behavioral consultation with parents and teachers. School Psychology Review, 29(3), 344-353.

Strauser, D. R., \& Wong, A. W. K. (2010). Impact not Efficacy: Applying the RE-AIM Framework to Rehabilitation Counseling Research. Rehabilitation Education, 24(3/4), 213-224. https://doi.org/10.1891/088970110805029750

Sugai, G., Horner, R. H., Dunlap, G., Hieneman, M., Lewis, T., Nelson, C., ... Wilcox, B. L. (2000). Applying positive behavioral support and functional assessment in schools. Journal of Positive Behavior Interventions, 2(3), 131-142. https://doi.org/10.1177/109830070000200302

Tustin, F. (1995). Autism and childhood psychosis. Karnac Books.

Wagner, P. (2000). Consultation: Developing a comprehensive approach to service delivery. Educational Psychology in Practice, 16(1), 9-18. https://doi.org/10.1080/026673600115229

Watson, P. J., \& Workman, E. A. (1981). The non-concurrent multiple baseline across-individuals design: An extension of the traditional multiple baseline design. J. Behav Ther Exp Psychiatry, 12(3), 257-259. https://doi.org/10.1016/0005-7916(81)90055-0

Wilkinson, L. A. (2003). Using behavioral consultation to reduce challenging behavior in classroom. Preventing School Failure: Alternative Education for Children and Youth, 47(3), 100-105. https://doi.org/10.1080/10459880309604437

Wilkinson, L. A. (2006). Conjoint behavioral consultation: An emerging and effective model for developing home-school based partnership. International Journal of Behavioral Consultation and Therapy, 2(2), 224-239. https://doi.org/10.1037/h0100778

Witt, J., Elliot, S., Daly, E., Gresham, F., \& Kramer, J. (1997). Assessment of At-Risk and Special Needs Children (2nd ed.). McGraw-Hill.

Yücesoy, Ş., \& Erbaş, D. (2002). İşlevi Kaçma Yoluyla Olumsuz Pekiştirme Olan Problem Davranışların Yer Aldığı Araştırmaların İncelenmesi. Ankara Üniversitesi Eğitim Bilimleri Fakültesi Özel Eğitim Dergisi, 3(2), 51-66.

\section{Copyrights}

Copyright for this article is retained by the author(s), with first publication rights granted to the journal.

This is an open-access article distributed under the terms and conditions of the Creative Commons Attribution license (http://creativecommons.org/licenses/by/4.0/). 